\title{
Bariatric Surgery for the Treatment of Diabetic Kidney Disease
}

\author{
William P Martin¹, Neil G Docherty ${ }^{2,3}$ and Carel W Le Roux ${ }^{2,3,4}$ \\ ${ }^{1}$ Department of Medicine, Galway University Hospitals, Saolta University Healthcare Group, Galway, Ireland \\ ${ }^{2}$ Conway Institute of Biomolecular and Biomedical Research, University College Dublin, Ireland \\ ${ }^{3}$ Department of Gastrosurgical Research and Education, University of Gothenburg, Sweden \\ ${ }_{4}^{4}$ Investigative Science, Imperial College London, UK
}

Submission: August 24, 2017; Published: August 29, 2017

*Corresponding author: Carel W Le Roux, Diabetes Complications Research Centre, Conway Institute of Biomolecular and Biomedical Research, School of Medicine, University College Dublin, Belfield, Dublin 4, Ireland, Tel: +3531-716-6831; Email: carel.leroux@ucd.ie

\begin{abstract}
Diabetic kidney disease is increasing in prevalence concordant with the inter-related diabetes and obesity pandemics. The potential mechanisms by which bariatric surgery may improve the course of diabetic kidney disease need to be understood to determine potential usefulness and risks of these interventions. Renal haemodynamics are altered in patients with diabetes and obesity and glomerular hyperfiltration is implicated as an initiating event in the genesis of renal functional decline. Effacement of glomerular podocyte foot processes and consequent albuminuria occur adaptively in response to glomerular hypertension, and when compounded by metabolic deregulation in the form of insulin resistance, hyperglycemia, and dyslipidaemia precipitate renal inflammation and oxidative stress.
\end{abstract}

Bariatric surgery may ameliorate the course of diabetic kidney disease by mitigating haemodynamic alterations, metabolic disturbances, renal oxidative stress, and renal inflammation concurrently. Glucagon-like peptide-1 may play a direct role in the renal functional improvements observed after bariatric surgery. The degree of weight loss necessary to improve the course of diabetic kidney disease in obese patients with diabetes, and the most effective mode by which to achieve weight loss for renal functional benefit, remain to be elucidated.

Keywords: Obesity; Type 2 diabetes mellitus; Diabetic kidney disease; Albuminuria; Podocyte; Glucagon-like peptide-1; Bariatric surgery

Abbreviations: DKD: Diabetic Kidney Disease; GBM: Glomerular Basement Membrane; GFB: Glomerular Filtration Barrier; GLP-1: GlucagonLike Peptide-1; MCP-1: Monocyte Chemoattractant Protein-1; RAAS: Renin-Angiotensin-Aldosterone System; RYGB: Roux-En-Y Gastric Bypass Surgery; T2DM: Type 2 Diabetes Mellitus

\section{Introduction}

The global pandemic of type 2 diabetes mellitus (T2DM) is considered one of the foremost challenges to healthcare delivery in the $21^{\text {st }}$ century. According to the latest International Diabetes Federation estimates, 415 million adults lived with diabetes mellitus globally in 2015 , a prevalence that is projected to rise to 642 million adults by 2040 [1]. The accelerated increase in T2DM incidence is closely linked to increasing central obesity at a population level [2]. Indeed, over $85 \%$ of individuals with T2DM are overweight or obese, resulting in the phenomenon referred to as 'diabesity' [3].

Chronic kidney disease is also increasing in prevalence as a consequence of the diabetes epidemic [4]. Indeed, according to US Renal Data System data, $43.9 \%$ of end-stage renal disease patients in the US have diabetes [5]. Although extensive research into the identification of biomarkers which predict progressive renal functional decline in diabetic kidney disease (DKD) is ongoing, two surrogate markers of renal function are currently used in clinical practice to monitor renal function in patients with diabetes: glomerular filtration rate and albuminuria. DKD is characterized by a slowly progressive decline in glomerular filtration rate accompanied by increasing albuminuria, with inexorable progression to end-stage renal disease over decades the norm [6]. Obesity itself, in the absence of comorbid diabetes, is associated with glomerular hyperfiltration and albuminuria [7].

Lifestyle modification programmes, medically supervised very-low calorie diets, drug treatments including glucagon-like peptide-1 (GLP-1) analogues, and bariatric surgery constitute the therapeutic hierarchy for obesity. The American Diabetes 
Association and International Diabetes Federation advocate for bariatric surgery in individuals with a BMI $\geq 30 \mathrm{~kg} / \mathrm{m}^{2}$ with difficult to control T2DM, provided non-surgical measures have proved unsuccessful [8]. Given that diabesity is widely prevalent and increasing numbers of bariatric surgical procedures are being performed globally, this presents an opportunity to study the impact of this intervention on DKD outcomes, something which promises to offer mechanistic insights into the pathophysiology of DKD and ultimately the translation of novel therapies to counter the disease.

\section{Pathogenic events in the glomerulus underpin the development of diabetic kidney disease}

Fenestrated glomerular endothelial cells lining the glomerular capillaries, the glomerular basement membrane (GBM), and terminally differentiated visceral epithelial cells of Bowman's capsule termed podocytes form the 3 layers of the glomerular filtration barrier (GFB), alterations in which are central to the pathogenesis of DKD. Normal daily excretion rates of albumin are less than $30 \mathrm{mg}$ when integrity of the GFB is intact; charge selectivity of the GFB is maintained by the glycocalyx of the glomerular endothelium and negatively charged proteoglycans in the GBM, while size selectivity of the GFB is created by cytoplasmic extensions of podocytes termed foot processes cross-bridging at specialized cellular junctions called slit diaphragms [9]. Podocyte injury, characterized by adaptive foot process effacement which compromises the slit diaphragms and GFB, is central to the onset and progression of albuminuria in obesity and diabetes [10].

Glomerular haemodynamics are altered in patients with obesity and diabetes due to activation of the reninangiotensin-aldosterone system (RAAS). Angiotensin IImediated efferent arteriolar vasoconstriction via $\mathrm{AT}_{1}$ receptors coupled with afferent arteriolar vasodilatation due to reduced tubuloglomerular feedback elevates intra-glomerular blood pressures and causes wall stress in the glomerular capillaries [11]. Increased renal plasma flow and increased renal venous pressure related to increased intra-abdominal pressure are observed in obese individuals, factors which also contribute to glomerular hypertension [12]. In vitro studies have revealed that the podocyte cytoskeleton reorganizes itself in response to mechanical stress in the glomerular capillaries to result in foot process effacement, something which compromises the GFB and serves as a nidus for the development of albuminuria [13].

DKD is increasingly recognized to occur in a complex inflammatory milieu involving multiple signaling pathways, powered by metabolic deregulation in the form of insulin resistance, hyperglycemia, and dyslipidaemia. Advanced glycation end products (AGEs) are formed non-enzymatically in the setting of impaired glycemic control when glucose reacts with the free amino groups of circulating and tissue proteins. Binding of AGEs to their receptors has been implicated in the progression of DKD by altering intracellular signaling, gene expression, and accelerating inflammation and oxidative stress to contribute to podocyte injury [14]. Adiponectin is an insulinsensitizing protein whose production by adipocytes is reduced through inflammatory mechanisms in obesity [15]. Adiponectin receptors are present on podocytes and appear to play a role in the maintenance of podocyte integrity in rodent models of obesity, such that adiponectin-deficient mice develop foot process effacement and consequent albuminuria [16].

\section{Impact of bariatric surgery and GLP-1 on podocyte function}

The beneficial impact of bariatric surgery on human DKD has been substantiated by mechanistic insights from rodent models. Unlike existing drug treatments for DKD such as RAAS inhibitors which target individual pathogenic mediators, bariatric surgery ameliorates the haemodynamic alterations, metabolic disturbances, oxidative stress, and pro-inflammatory mechanisms which perpetuate DKD concurrently.

The reduction in albuminuria post-Roux-en-Y gastric bypass surgery (RYGB) correlates with blood pressure reductions [17]. Navarro-Diaz et al. demonstrated sustained reductions in glomerular hyperfiltration and albuminuria at 24 months postbariatric surgery in extremely obese individuals with a mean BMI of $53.62 \mathrm{~kg} / \mathrm{m}^{2}$ [18]. Although the majority of weight loss and reduction in glomerular hyperfiltration occurred in the first year post-surgery, albuminuria continued to decrease in the second postoperative year, suggesting that podocyte function may continue to improve remote from when its injurious stressor has been removed.

Furthermore, glycemic and lipid parameters, potent stimulators of ongoing inflammation and progression in DKD, improve dramatically post-bariatric surgery $[19,20]$. Bariatric surgery also reduces renal inflammation, with significant early reductions in urinary cytokines (migration inhibitory factor, monocyte chemotactic protein-1 (MCP-1), and chemokine ligand-18) observed at 4 weeks after a variety of bariatric surgical procedures, including laparoscopic adjustable gastric banding, RYGB, and sleeve gastrectomy [21]. MCP-1 mRNA expression increases in animal models of DKD and localizes to the podocyte [22]. Thus, its expression is reflective of podocyte injury and its reduction post-bariatric surgery indicates improvement in podocyte function.

Bariatric surgery may also have renoprotective effects through novel endocrine mechanisms. The post-prandial response to GLP-1 is increased following RYGB, resulting in increased glucose-dependent insulin secretion, reduced glucagon secretion, and delayed gastric emptying [23].These GLP-1 effects enhance glycemic control and the sensation of satiety postoperatively, which by themselves may ameliorate the dysmetabolic and inflammatory milieu of DKD. More direct renoprotective effects of GLP-1 are increasingly recognized, however. GLP-1 inhibits proximal tubular sodium reabsorption, increases distal renal tubular sodium delivery, 


\section{Current Research in Diabetes \& Obesity Journal}

activates tubuloglomerular feedback, and increases afferent arteriolar resistance which attenuates glomerular hypertension [24]. Interestingly, sodium-glucose cotransporter-2 (SGLT2) inhibitors have a similar natriuretic effect in the proximal tubule [24], and both Liraglutide (GLP-1 analogue) and Empagliflozin (SGLT2 inhibitor) have demonstrated renoprotective benefits additional to RAAS inhibitors in randomized, placebo-controlled trials in patients with T2DM $[25,26]$. GLP- 1 analogues have also been shown to reduce renal oxidative stress and consequent albuminuria by down-regulating NADPH oxidase activity in a rodent model of DKD [27].

Despite recent advances, much remains unknown about the impact of bariatric surgery and other obesity interventions on DKD progression. The degree of weight loss necessary to slow, or even reverse, the course of DKD along with other microvascular complications of T2DM remains to be elucidated. Furthermore, the relative efficacy of various weight loss interventions such as lifestyle modification programmes, very low-calorie diets, drug treatments including GLP-1 analogues, and the assortment of bariatric surgeries on slowing the course of DKD progression should be investigated. Serum and urinary biomarkers which identify obese T2DM patients at high risk for DKD progression, and which can be monitored to determine response to therapy, are actively being investigated.

\section{Conclusion}

Podocyte dysfunction is central to the pathogenesis of DKD, and results from a complex interplay of haemodynamic, metabolic, and inflammatory disturbances which are accelerated in the presence of obesity. Bariatric surgery improves markers of renal dysfunction such as albuminuria and glomerular hyperfiltration in human DKD. The degree of weight loss necessary to slow DKD progression in obese T2DM patients and the relative efficacy of obesity interventions on DKD course remain to be elucidated.

\section{References}

1. International Diabetes Federation (2015) IDF Diabetes Atlas ( $7^{\text {th }}$ edn), International Diabetes Federation, Brussels, Belgium..

2. Zimmet PZ (2017) Diabetes and its drivers: the largest epidemic in human history? Clin Diabetes Endocrinol 3: 1.

3. Daousi C, Casson IF, Gill GV, MacFarlane IA, Wilding JP, et al. (2006) Prevalence of obesity in type 2 diabetes in secondary care: association with cardiovascular risk factors. Postgrad Med J 82 (966): 280-284.

4. Hill NR, Samuel Fatoba T, Jason Oke L, Jennifer Hirst A, Christopher A, et al. (2016) Global Prevalence of Chronic Kidney Disease - A Systematic Review and Meta-Analysis. PLoS One 11(7): e0158765.

5. Saran R, Li Y, Robinson B, Abbott KC, Agodoa LY, et al. (2016) US renal data system 2015 annual data report: epidemiology of kidney disease in the United States. Am J Kidney Dis 67(3 Suppl 1): Svii, S1-305.

6. Pugliese G (2014) Updating the natural history of diabetic nephropathy. Acta Diabetol 51(6): 905-915.

7. D'Agati VD, Chagnac A, de Vries AP, Levi M, Porrini E, et al. (2016) Obesity-related glomerulopathy: clinical and pathologic characteristics and pathogenesis. Nat Rev Nephrol 12(8): 453-471.
8. (2014) National Institute for Health and Care Excellence. Obesity: identification, assessment and management. NICEG guideline (CG189), London.

9. Menon MC, Chuang PY, He CJ (2012) The glomerular filtration barrier: components and crosstalk. Int J Nephrol 2012: 749010.

10. Li J, Kwak SJ, Jung DS, Kim J, Yoo TH, et al. (2007) Podocyte biology in diabetic nephropathy. Kidney Int Suppl (106): S36-42.

11. Siragy HM, Carey RM (2010) Role of the intrarenal renin-angiotensin-aldosterone system in chronic kidney disease. Am J Nephrol 31(6): 541-550.

12. Wickman C, H Kramer (2013) Obesity and kidney disease: potential mechanisms. Semin Nephrol 33(1): 14-22.

13. Endlich N, Kress KR, Reiser J, Uttenweiler D, Kriz W, et al. (2001) Podocytes responds to mechanical stress in vitro. J Am Soc Nephrol 12(3): 413-422.

14. Singh VP, Anjana B, Nirmal S, Amteshwar Singh J (2014) Advanced Glycation End Products and Diabetic Complications. Korean J Physiol Pharmacol 18(1): 1-14.

15. Kawano J, Arora R (2009) The role of adiponectin in obesity, diabetes, and cardiovascular disease. J Cardiometab Syndr 4(1): 44-49.

16. Sharma K, Ramachandrarao S, Qiu G, Usui HK, Zhu Y, et al. (2008) Adiponectin regulates albuminuria and podocyte function in mice. J Clin Invest 118(5): 1645-1656.

17. Schauer PR, Bhatt DL, Kashyap SR, Kathy Wolski, Ali Aminian, et al (2014) Bariatric surgery versus intensive medical therapy for diabetes. N Engl J Med 371(7): 682.

18. Navarro Diaz M, Serra A, Romero R, Bonet J, Bayés B, et al. (2006) Effect of drastic weight loss after bariatric surgery on renal parameters in extremely obese patients: long-term follow-up. J Am Soc Nephrol 17(12 Suppl 3): S213-S217.

19. Umeda LM, Silva EA, Carneiro G, Arasaki CH, Geloneze B, et al. (2011) Early improvement in glycemic control after bariatric surgery and its relationships with insulin, GLP-1, and glucagon secretion in type 2 diabetic patients. Obes Surg 21(7): 896-901.

20. Garcia Marirrodriga I, Amaya Romero C, Ruiz Diaz GP, Férnandez S, Ballesta López C, et al. (2012) Evolution of lipid profiles after bariatric surgery. Obes Surg 22(4): 609-616.

21. Bueter M, Dubb SS, Gill A, Joannou L, Ahmed A, et al. (2010) Renal cytokines improve early after bariatric surgery. Br J Surg 97(12): 18381844

22. Chow F, Ozols E, Nikolic Paterson D, Atkins RC, Tesch GH, et al. (2004) Macrophages in mouse type 2 diabetic nephropathy: correlation with diabetic state and progressive renal injury. Kidney Int 65(1): 116-128.

23. Baggio L, Drucker DJ (2007) Biology of incretins: GLP-1 and GIP. Gastroenterology 132(6): 2131-2157.

24. Muskiet MH, Lennart Tonneijck, Mark M Smits, Mark H Kramer, Hiddo J Lambers, et al. (2015) Pleiotropic effects of type 2 diabetes management strategies on renal risk factors. Lancet Diabetes Endocrinol 3(5): 367-381.

25. Marso SP, Daniels GH, Brown Frandsen K, Kristensen P, Mann JF, et al. (2016) Liraglutide and cardiovascular outcomes in type 2 diabetes. $N$ Engl J Med 375(4): 311-322.

26. Wanner C, Silvio Inzucchi E, John Lachin M, David Fitchett, Maximilian von Eynatten, et al. (2016) Empagliflozin and progression of kidney disease in type 2 diabetes. N Engl J Med 375(4): 323-334.

27. Fujita H, Morii T, Fujishima H, Sato T, Shimizu T, et al. (2014) The protective roles of GLP-1R signaling in diabetic nephropathy: possible mechanism and therapeutic potential. Kidney Int 85(3): 579-589. 
This work is licensed under Creative Commons Attribution 4.0 Licens

DOI: 10.19080/CRDOJ.2017.3.555624
Your next submission with Juniper Publishers will reach you the below assets

- Quality Editorial service

- Swift Peer Review

- Reprints availability

- E-prints Service

- Manuscript Podcast for convenient understanding

- Global attainment for your research

- Manuscript accessibility in different formats (Pdf, E-pub, Full Text, Audio)

- Unceasing customer service

Track the below URL for one-step submission https://juniperpublishers.com/online-submission.php 